\title{
LES of a Sooting Flame in a Pressurized Swirl Combustor
}

\author{
Heeseok Koo* and Venkat Raman ${ }^{\dagger}$ \\ University of Michigan, Ann Arbor, Michigan, 48105, USA \\ Michael E. Mueller \\ Princeton University, Princeton, New Jersey, 08544, USA \\ Klaus Peter Geigle ${ }^{\S}$ \\ Institute of Combustion Technology, Pfaffenwaldring 38-40, D-70569 Stuttgart, Germany
}

\begin{abstract}
Large eddy simulations (LES) of a model aircraft combustor at different pressure and operating conditions are conducted. Detailed models for soot formation and evolution is used along with minimally-dissipative numerical schemes in a fully unstructured mesh simulation of this complex geometry flow. Two slightly different swirl combustors, one operated at atmospheric pressure and the other at higher pressures (3-5 bars) are used. Both combustors are stabilized by strong swirl generated by inlet swirlers. In both cases, a set of secondary injection ports are present that mimic the rich-quench-lean combustor design. The objective of this work is to explore the role of soot trajectories on the intermittent nature of particulate generation. It is found that soot intermittency comes from the trajectories traveled by the soot particles. Only a small portion of the combustor exhibit conditions suitable for soot particle growth. Due to the chaotic nature of the turbulent flow, only a small fraction of the fluid elements pass through this region, which leads to spatial and temporal intermittency. Simulations at various pressures show that with increasing pressure, jet breakdown and mixing is more efficient, which somewhat curtails the generation of fuel-rich pockets needed for particle growth. It is also observed that intensity of soot-turbulence interaction becomes stronger as the operating pressure increases.
\end{abstract}

\section{Introduction}

Soot generation in aircraft engines is a complex process that is caused essentially through inefficiencies in turbulent mixing of fuel and air. Since most aircraft combustors operate at fuel-lean conditions (globally), and soot forms only in fuel-rich conditions, generation of particulates happens in specific regions of the combustor that can contain fuel-rich pockets. Additionally, the physical and chemical processes that drive particle formation and growth are slower compared to the fuel oxidation process, implying that soot-favorable conditions have to exist in the combustor for a substantial time in order to generate significant soot at the combustor exit. The main driving factor for such emissions is that practical combustors operate at high pressures (20-40 atm). Typically soot formation scales as $P^{n}$, where $n$ can range from $1-3$ depending on the fuel and the local flow conditions. Hence, even if favorable conditions exist only for a short time-spans, it can effectively convert fuel-bound carbon to particulates.

Past studies of soot formation have been overwhelmingly in laminar flames operating at both laminar and high pressure conditions. ${ }^{1}$ From these studies, it has been established that a pressure increase leads to superlinear increase in soot volume fraction. From a fundamental perspective, such a growth comes from the increase of concentration of PAH molecules ${ }^{2}$ as well as the increased surface growth due to acetylene-based addition.

\footnotetext{
*Postdoctoral Researcher, Department of Aerospace Engineering, Member, AIAA.

${ }^{\dagger}$ Associate Professor, Department of Aerospace Engineering, Senior Member, AIAA.

$¥$ Assistant Professor, Department of Mechanical and Aerospace Engineering, Member, AIAA.

$\S$ Senior Researcher, German Aerospace Center (DLR), Member, AIAA.
} 
Essentially, all the increase comes from kinetic rates associated with soot formation. In the recent past, there has been increased focus on turbulent sooting flames. ${ }^{3-6}$ However, these canonical jet flames operate in such a way that soot forms in more or less laminar-like regions with very limited multi-scale features that highly turbulent flows normally possess. To understand soot formation under realistic flow conditions, Geigle and co-authors $^{7-10}$ developed a model aircraft combustor that replicates the rich-quench-lean (RQL) gas turbine design. Here, a swirl stabilized flame operating at different pressures was studied. Further, a set of dilution holes were used to replicated secondary dilution air injection in the RQL design.

Koo et al. ${ }^{11-13}$ have previously studied this combustor using detailed soot models and large eddy simulation (LES) methodology. From both the simulations and experiments, it is increasingly clear that hydrodynamics can introduce another important scaling parameter for soot formation. It was found that with increasing pressure, the flow features of the combustor changes, thereby altering the fraction of fuel-rich pockets that reside in hightemperature zone, which is an important indicator of sooting tendency. It was also determined that flame shape changes are not continuous in pressure, implying that there could be step changes in flow features between two different conditions leading to extremely different sooting behavior. In other words, pressure scaling in turbulent aircraft combustors is the product of two different scaling laws $P^{n} P^{m}$, where $m$ is a measure of the hydrodynamic factor that favors soot formation. This would imply that design choices could be used to reduce the impact of kinetics-related soot growth if the hydrodynamic factor is negative.

The hydrodynamic factor is directly related to the concept of intermittency. ${ }^{5,14}$ In turbulent sooting flames, it is commonly observed that soot formation is sporadic, with formation events associated with large soot volume fractions even separated by integral time scales. This relates to the fundamental notion that in globally lean combustors, the probability of finding fuel-rich long residence-time events is low. Consequently, only for a small-fraction of the total operating time, soot generation is important. Additionally, soot precursor formation is highly sensitive to the local dissipation structure. ${ }^{15}$ Since this dissipation rate is a highly fluctuating quantity in turbulent flows, it is possible that precursor formation happens only infrequently.

With this background, the focus of this study is to explore the role of hydrodynamics on the intermittent nature of particulate generation. In particular, the DLR combustor for a wide range of operating conditions is used to understand the trajectories that soot particles traverse in physical and compositional spaces. From this, the role of hydrodynamics in amplifying or suppressing soot formation with increase in pressure is analyzed. As in previous studies, the DLR model combustor ${ }^{8}$ is studied here.

\section{DLR model combustor and simulation details}

\section{A. Flow configuration}

For the purposes of this study, two different DLR configurations are considered. The first configuration contains atmospheric pressure data, while the second configuration includes pressurized experiments. The atmospheric pressure and the pressurized ethylene-fuel based DLR model aircraft combustor configurations are shown schematically in Fig. 1. ${ }^{7-9}$ Both configurations include two oxidizer air streams from the bottom and fuel ports between those two air streams. The main differences between the two configurations are the axial location of the fuel ports and the ability to control flow rate between the two air streams. In the pressurized combustor, fuel ports are located coincident with the chamber bottom wall, and the inner and outer air streams (called central and ring airs) are separated. A set of injection ports with diameters of $3.5 \mathrm{~mm}$ are located on the sidewalls that introduce secondary air similar to the RQL design for aircraft combustors. For the studies discussed below, only atmospheric pressure case considers the effect of the secondary air streams. The main chamber measures $110 \mathrm{~mm}$ in height with a square section of $85 \times 85 \mathrm{~mm}^{2}$ for the atmospheric combustor whereas the pressurized chamber is slightly narrower and taller, spanning $120 \mathrm{~mm}$ in height with a square cross-section measuring $68 \times 68$ $\mathrm{mm}^{2}$.

Table 1 summarizes flow conditions of the cases studied in this paper. From the experiment, soot volume fraction data is available across all the simulated cases while velocity and temperature measurements are provided for selected cases. First two cases are from the atmospheric pressure configuration (left of Fig. 1) and the last two cases use the pressurized combustor (right of Fig. 1). 

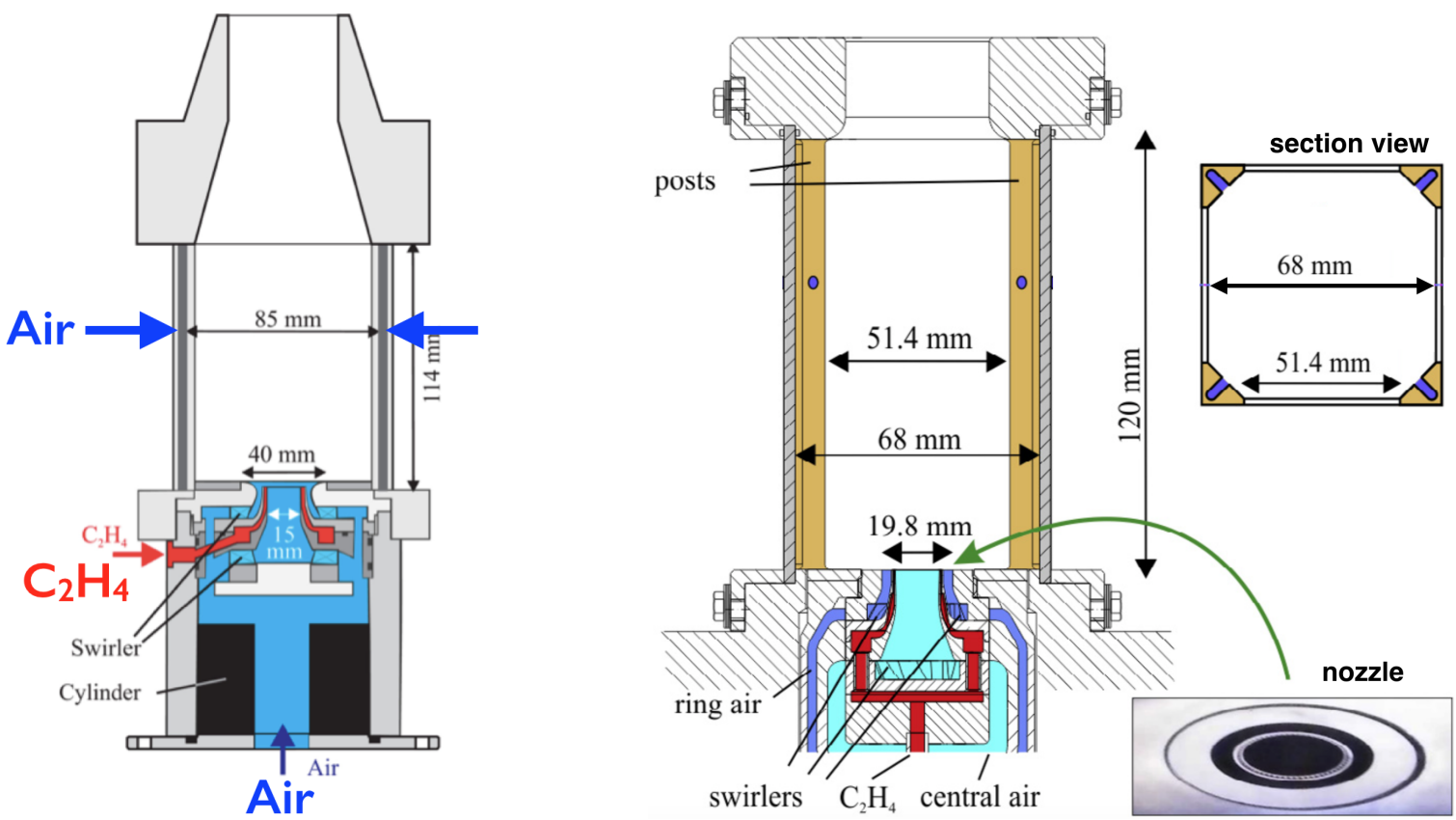

Figure 1. Burner geometries for the cases of (left) 1 bar and (right) 3 and 5 bars. High pressure schematic on the right additionally offers nozzle details, and cross sections at the height of oxidation air injection and the middle of the chamber.

\begin{tabular}{|l|l|l|l|l|l|}
\hline Case name & $\begin{array}{l}\mathrm{P} \\
(\text { bar })\end{array}$ & $\begin{array}{l}\mathrm{Q}_{\text {air }} \\
(\mathrm{slpm})\end{array}$ & $\begin{array}{l}\mathrm{Q}_{\text {fuel }} \\
(\mathrm{slpm})\end{array}$ & $\begin{array}{l}\mathrm{Q}_{\text {secondary jet }} \\
(\mathrm{slpm})\end{array}$ & $\phi_{\text {global }}$ \\
\hline 1 bar & 1 & 150 & 15.7 & 0 & 1.5 \\
1 bar with secondary jet & 1 & 150 & 15.7 & 44.9 & 1.15 \\
3 bar & 3 & $140.8($ central $)+328.5(\mathrm{ring})$ & 39.3 & 0 & 1.2 \\
5 bar & 5 & $234.2($ central $)+546.2(\mathrm{ring})$ & 65.4 & 0 & 1.2 \\
\hline
\end{tabular}

Table 1. Flow parameters used for the simulations. $\phi_{\text {global }}$ indicates the global equivalence ratio for these inflow conditions.

\section{B. Model and simulation details}

In this study, LES is used to describe the turbulent flow as well as the gas phase composition and soot moments equations. The gas-phase combustion is described using a flamelet-progress variable approach, ${ }^{16}$ where a set of unsteady one-dimensional flamelets are tabulated for look-up in the computation. To account for radiation effects, enthalpy loss is also included in the flamelet approach. ${ }^{17} \mathrm{~A}$ bivariate distribution with volume and surface as the internal coordinates is used to track the soot population. The evolution equations and associated rates are based on the model proposed by Mueller. ${ }^{18-20}$ The number density is described in terms of a finite set of moments, ${ }^{19}$ which are solved in the filtered form along with the gas-phase mass, momentum, and flamelet-related variables. The nucleation model is based on dimerization, ${ }^{21}$ while soot growth is through surface growth ${ }^{22}$ as well as PAH condensation. ${ }^{19}$

The LES equations for soot moments and scalar fields are implemented in an OpenFOAM package ${ }^{13}$ which has been validated through a number of studies. ${ }^{11,25-27}$ This package, called unFlameletFoam, improves the pressure-projection algorithm of a low Mach number formulation to preserve continuity in the system under variable density conditions. The solver is capable of solving stiff variable density cases. ${ }^{28}$ Furthermore, it minimizes numerical dissipation of secondary properties such as kinetic energy by adopting a skew-symmetric form for the convective terms that was developed specifically for compressible flows. ${ }^{13,29}$ The improved solver provides much better comparison with experiments as compared to the results reported in Koo et al. ${ }^{11}$ These 
newer results have been reported separately in Koo et al., ${ }^{13}$ and are discussed here briefly for the sake of clarity.

Figure 2 shows the computational meshes used in this work. The number of computational volumes was 5-7 million based on the cases studied. The main combustor itself is geometrically simple, but the inflow ducts that pass through the swirler are highly intricate and geometrically complex. It was found that the flow profile at the exit of the inflow nozzles directly affects the size of the recirculation zone and the stability of the combustion processes. For this reason, several grids were used to understand the impact of numerical discretization on the spatial evolution of the swirling flow. The computational mesh used here was found to provide the best performance with minimal grid size. The LES computations were performed on 256 cores, with each simulation taking roughly 100 hours. Statistics were collected after ten flow-through times had passed. Soot statistics presented in the results section (Sec. III) are averaged in the four homogeneous directions from the centerline to the walls along two orthogonal planes normal to the side walls.
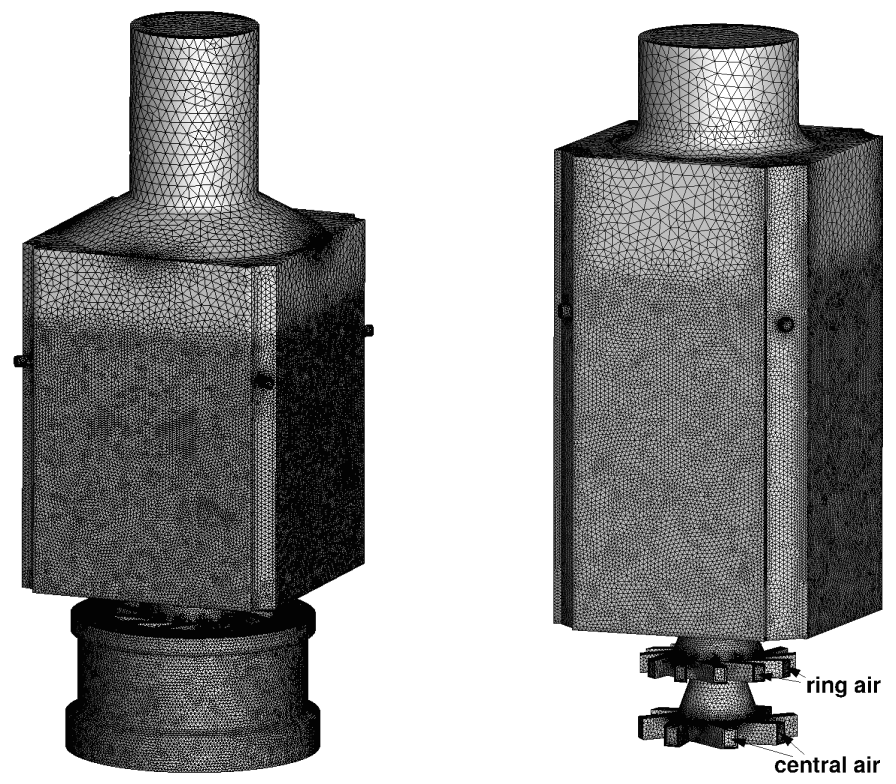

Figure 2. Computational meshes for (left) the atmospheric pressure and (right) the pressurized LES.

\section{Results and discussion}

In this section, the LES results are first discussed first in order to motivate the analysis of Lagrangian results and intermittency effects in these combustors.

\section{A. Gas-phase and soot statistics}

In this work, only the combustion and soot statistics are presented. The velocity fields were found to match the experiments very accurately for the atmospheric cases ${ }^{13}$ and the pressurized cases ${ }^{12}$ very accurately, considering the complexity of the geometry and the ensuing flow. Time-averaged mixture fraction contours of the four cases are shown in Fig. 3. Overall, the fuel jet bends toward the side walls due to the swirling inner flow. Locations where mean axial velocity is negative represent recirculating flows. In particular, the large recirculating area in the middle of the chamber is termed inner recirculation zone for the current discussion, and offers long flow residence times. The inflow streams are nearly-fully mixed inside the inner recirculation zone for all the cases. The secondary jet changes the mean mixture fraction in the inner recirculation zone, pushing this region from fuel-rich to fuel-lean conditions (Fig. 3 (b)).

Figure ?? shows soot results of the high pressure cases. Peak location for the soot volume fraction occurs along the jet, with a delay from the fuel injection point due to both mixing and slow soot chemistry effects. Further downstream, most of the soot particles are oxidized by fuel-lean conditions. Consequently, there is 


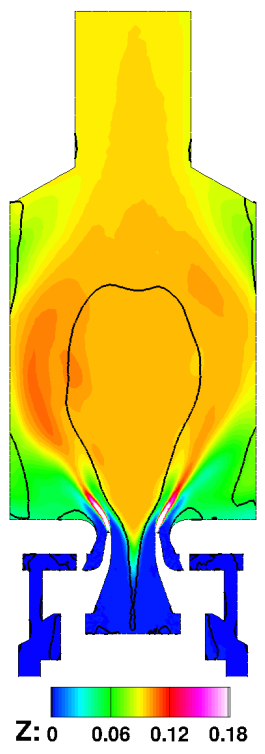

(a) 1 bar

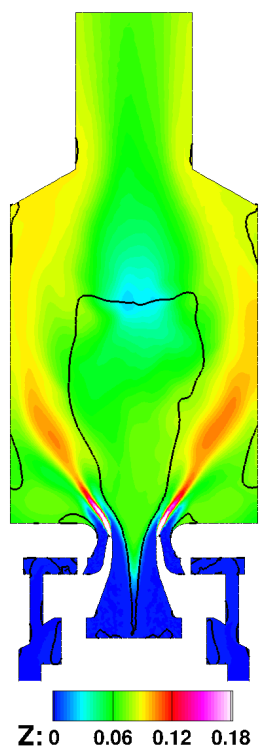

(b) 1 bar with secondary jet

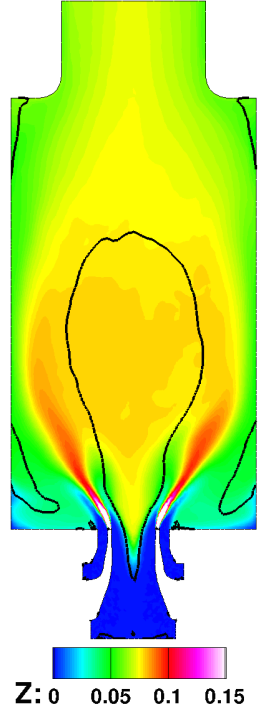

(c) 3 bar

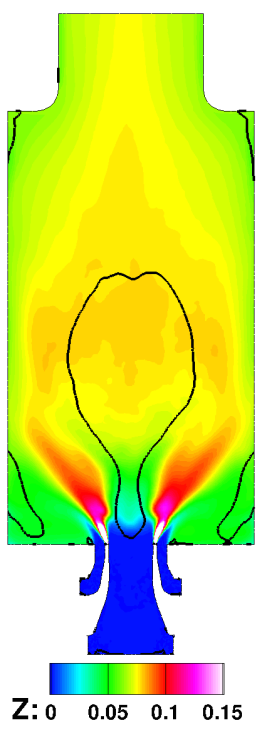

(b) 5 bar

Figure 3. Time-averaged contours mixture fraction. Mean axial velocity is zero along the solid lines.

almost no soot that enters the recirculation zone from the downstream edge of the fuel jet. This behavior is different from what is observed in the experiment, in that there are substantial amount soot that reside even after the flow recirculation. The soot is accumulated at the bottom of the inner recirculation zone, where the maximum soot volume fraction occurs. In fact, peak soot volume fraction is 3 to 14 times under-predicted in LES. It is therefore presumed that oxidation is much more pronounced in the simulations as compared to experiments.

Given the similarity of flow configurations, it is interesting to note that soot is over-predicted in the atmospheric pressure cases (Fig. ??) while it is under-predicted in the other two cases (Fig. ??). The notable difference between the cases is the mixture fraction values that the soot particles encounter along their trajectories. A scatter plot between soot volume fraction and mixture fraction is shown in Fig. 4 for the 1 bar case without secondary jet. Note that stoichiometric mixture fraction for the ethylene-air jet is 0.064 . Soot volume fraction peaks around mixture fraction of 0.11 , or an equivalence ratio of 1.6. This is unaltered across all the simulations and is explained by the fact that surface growth is maximum near these values (Fig. ??). Timeaveraged mixture fraction contours (Fig. 3) show different tendencies between the pressurized and atmospheric cases. Mixture fraction in the inner recirculation zone of the 1 bar case is nearly uniform at 0.1 and the value is slightly higher along the jet. In fact, the global equivalence ratio of this case is 1.5 , and the main flow path is exposed to a soot-favorable condition. Although the global equivalence ratio of the 1 bar with secondary jet case is the lowest amongst all cases (1.15), the main flow path along the jet still exhibits high mixture fraction values farther downstream due to the flow structure. Since soot volume fraction is proportional to the time spent in fuel-rich gas phase conditions, this long exposure to soot-favorable conditions leads to higher local soot volume fraction in the atmospheric pressure cases as compared to the pressurized cases. Conversely, high mixture fraction values are not observed in the pressurized cases, where the jet breakdown occurs faster due to higher Reynolds number (Fig. 3. Therefore, soot growth is inhibited even though the rate of growth is higher due to higher pressure. It is this competing hydrodynamic and kinetic effect that is critical in determining the pressure scaling of turbulent sooting flames.

\section{B. Statistics of soot evolution}

Time averaged soot number density, volume moments, and selected soot sources are shown in Figs. 5 to 8 in the order of the four cases listed in Tab. 1. Soot sources considered are nucleation, condensation, surface growth, and oxidation, which affect soot mass. Note that coagulation and fragmentation are not included in the 


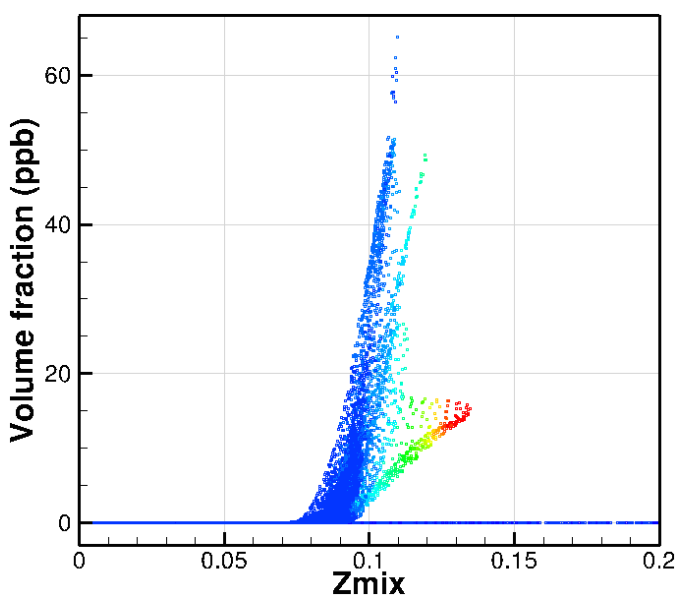

Figure 4. Scatter plot of soot volume fraction conditioned on mixture fraction, colored by soot particle number density.

discussion since these two processes do not contribute to a change in soot mass. Axial locations along the jet can be considered as surrogates for the sequence of physical processes that are active. For all cases, the order of physical processes appears to be nucleation, condenation, surface growth and followed by oxidation. While this appears obvious in hind-sight, the complex flow structure could change the physical location and importance of these processes. The highest soot number density is observed very close to the nucleation zone, after which agglomeration reduces this quantity.

For the atmospheric pressure case, the effect of secondary jet injection is shown in Figs. 5 and 6 . Most of the soot is generated along the side walls for both cases. The secondary jet oxidizes the flow in the inner recirculation zone by suppressing most of soot evolution process (Fig. 6). However for the case without secondary jet, condensation and surface growth are still active when the flow progresses towards the inner recirculation zone. Therefore, the peak soot volume fraction occurs at the upper part of the recirculation zone.
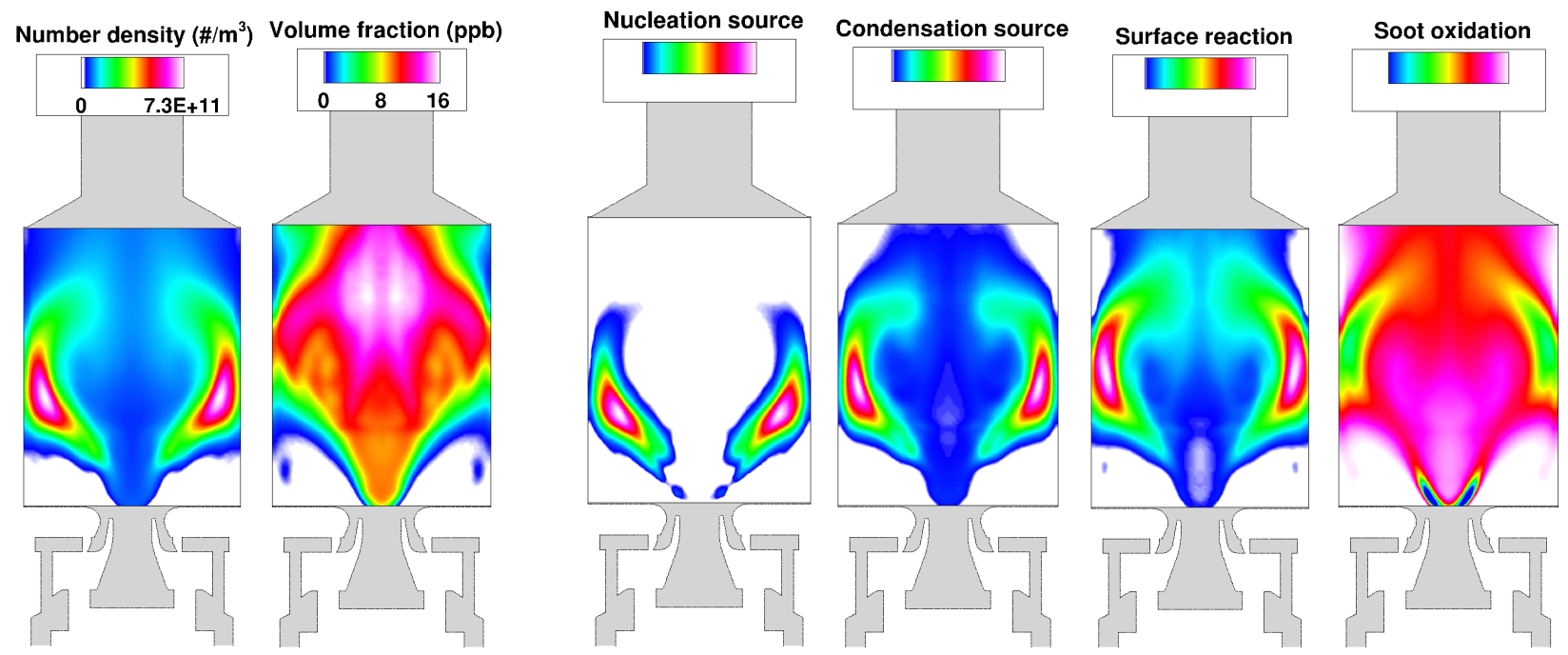

Figure 5. Soot moments and evolution sources averaged for 1 bar case without secondary jet.

Compared to the 1 bar case, the pressurized flames produce soot far sooner, with the soot nucleation region located closer to the fuel injection port (Figs. 7 and 8). The peak nucleation occurs in the middle between the jet and the side wall ( 3 bar) or very close from the jet injection $(5 \mathrm{bar})$. Considering that nucleation peaks 

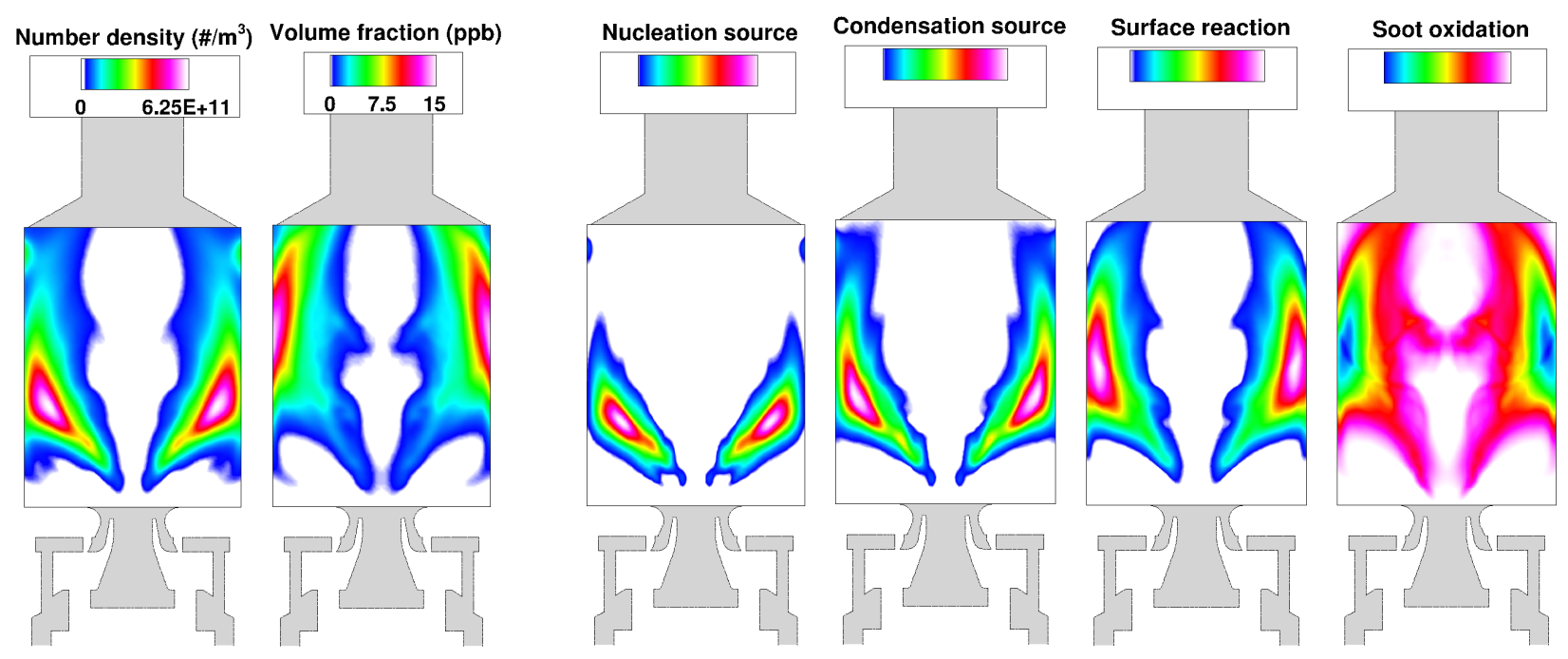

Figure 6. Soot moments and evolution sources averaged for 1 bar case with the secondary jet.

where the jet reaches the side wall in the 1 bar case in Fig. 5, the pressurized combustor is seen to enhance soot generation. The area of soot generation appears wider in the 5 bar case compared to the 3 bar case. This indicates that turbulent fluctuations in the flow field lead to a widening of the soot generation region. More interestingly, the soot oxidation process also occurs earlier, with most of the soot volume oxidized before entering the inner recirculation zone. Therefore, the operating pressure impacts not only the speed of soot evolution, but also the location where soot is formed.
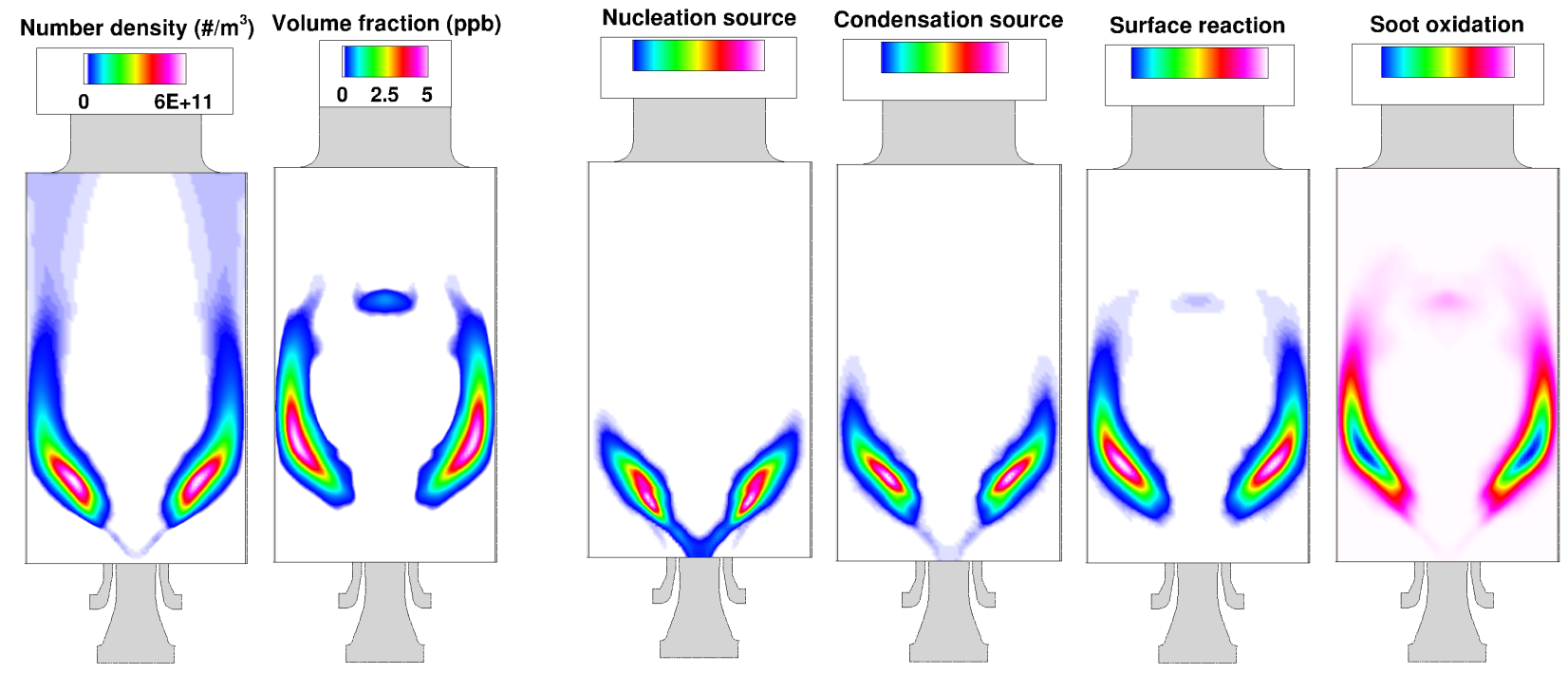

Figure 7. Soot moments and evolution sources averaged for the 3 bar case.

\section{Conclusion}

In this work, LES of a sooting turbulent flame in a swirling combustor is conducted for different pressure and flow conditions. The focus is on the intermittent nature of soot formation. It is found that such intermittency comes from the trajectories traveled by the soot particles. Only a small portion of the combustor exhibits 

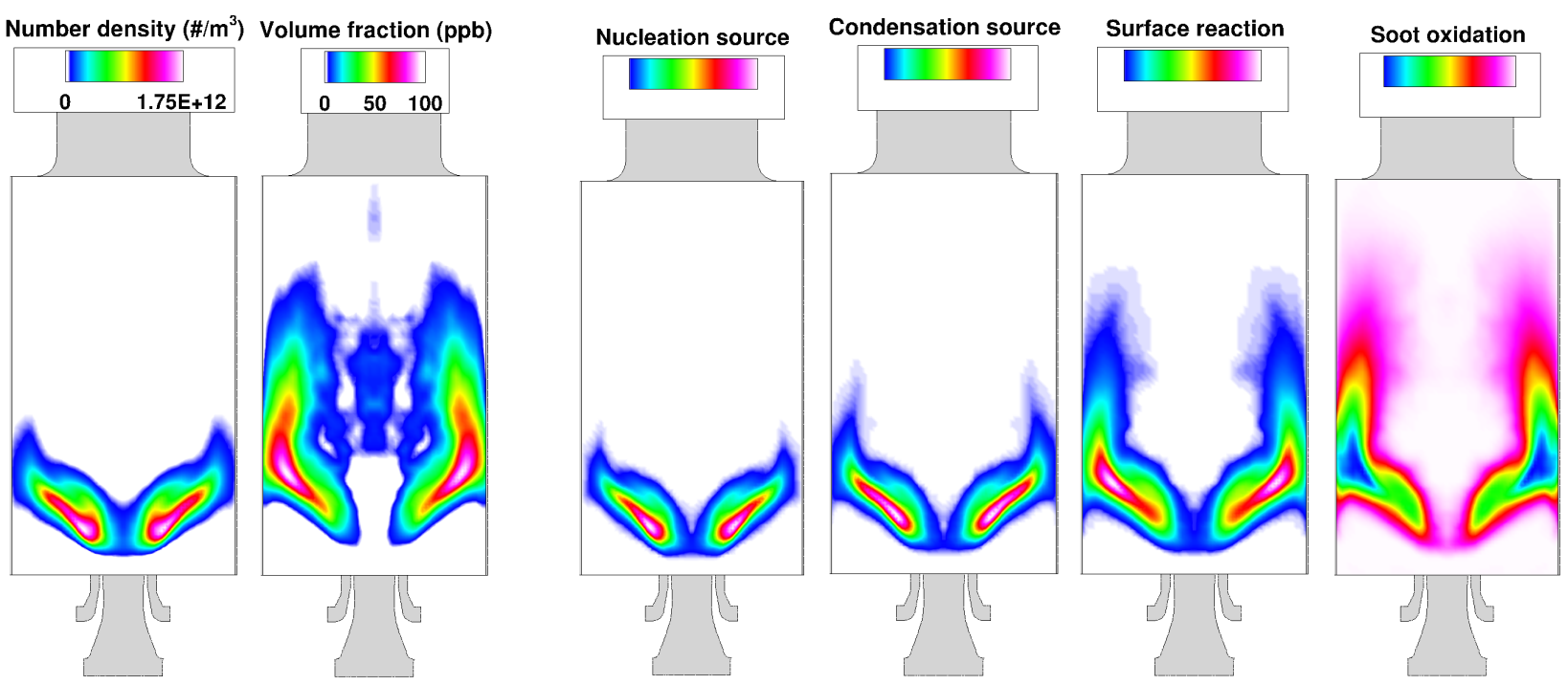

Figure 8. Soot moments and evolution sources averaged for the 5 bar case.

conditions suitable for soot particle growth. Due to the chaotic nature of the turbulent flow, only a small fraction of the fluid elements passes through this region, which leads to spatial and temporal intermittency. Analysis of particulate source terms show that much of the growth happens very early in the soot trajectory, with oxidation dominating at later times. Results at various flow conditions and pressures indicate that global equivalence ratio and the dominant fuel-air mixture fraction value along the jet determines under-prediction or over-prediction of the soot volume fraction in LES. In particular, soot-favorable flow condition tends to increase soot growth in the simulation. Simulations at various pressures show that with increasing pressure, jet breaks faster and mixing is more efficient, which somewhat curtails the generation of fuel-rich pockets needed for particle growth. On the other hand, increased kinetic rates lead to soot formation even when the probability of finding soot-favorable conditions are lower.

\section{Acknowledgements}

HK and VR were supported through a Strategic Environmental Research and Development (SERDP) grant (WP-2151) with Dr. Robin Nissan as the contract monitor. The authors also gratefully acknowledge the generous allocation of computing time by the Texas Advanced Computing Center and the NASA High-End Computing (HEC) Program through the NASA Advanced Supercomputing (NAS) Division at Ames Research Center.

\section{References}

\footnotetext{
${ }^{1}$ Karatas, A. E. and Gulder, O. L., "Soot formation in high pressure laminar diffusion flames," Progress in Energy and Combustion Science, Vol. 38, No. 2, 2012, pp. 818-845.

${ }^{2}$ Consalvi, J.-L. and Liu, F., "Numerical study of the effects of pressure on soot formation in laminar coflow n-heptane/air diffusion flames between 1 and $10 \mathrm{~atm}, "$ Proceedings of the Combustion Institute, Vol. 35, No. 2, 2015, pp. 1727-1734.

${ }^{3}$ Merci, B., Roekaerts, D., Peeters, T. W. J., and Dick, E., "The impact of the turbulence model and inlet boundary conditions on calculation results for reacting flows," Proceedings of the Fifth International Workshop on Measurement and Computation of Turbulent Non-premixed Flames, Delft, The Netherlands, 2000, pp. 226-227.

${ }^{4}$ Mueller, M. E., Chan, Q. N., Qamar, N. H., Dally, B. B., Pitsch, H., Alwahabi, Z. T., and Nathan, G. J., "Experimental and computational study of soot evolution in a turbulent nonpremixed bluff body ethylene flame," Combustion and Flame, Vol. 160, 2013, pp. 1298-1309.

${ }^{5}$ Qamar, N., Alwahabi, Z., Chan, Q., Nathan, G., Roekaerts, D., and King, K., "Soot volume fraction in a piloted turbulent jet non-premixed flame of natural gas," Combustion and Flame, Vol. 156, No. 7, 2009, pp. 1339-1347.

${ }^{6}$ The second international sooting flame workshop, 2014.

${ }^{7}$ Geigle, K. P., Zerbs, J., Kohler, M., Stohr, M., and Meier, W., "Experimental analysis of soot formation and oxidation in a gas turbine model combustor using laser diagnostics," Journal of Engineering for Gas Turbines and Power, Vol. 133, 2011,
} 
pp. 121503.

${ }^{8}$ Geigle, K. P., Hadef, R., and Meier, W., "Soot Formation and Flame Characterization of an Aero-Engine Model Combustor Burning Ethylene at Elevated Pressure," Journal of Engineering for Gas Turbines and Power, Vol. 136, 2014 , pp. 021505.

${ }^{9}$ Geigle, K. P., Kohler, M., O'Loughlin, W., and Meier, W., "Investigation of soot formation in pressurized swirl flames by laser measurements of temperature, flame structures and soot concentrations," Proceedings of the Combustion Symposium, Vol. 35, 2015, pp. 3373-3380.

${ }^{10}$ Geigle, K. P., O'Loughlin, W., Hadef, R., and Meier, W., "Visualization of soot inception in turbulent pressurized flames by simultaneous measurement of laser-induced fluorescence of polycyclic aromatic hydrocarbons and laser-induced incandescence, and correlation to OH distributions," Applied Physics B, Vol. 119, No. 4, 2015, pp. 717-730.

${ }^{11}$ Koo, H., Raman, V., Mueller, M. E., and Geigle, K. P., "Large-eddy simulation of a turbulent sooting flame in a swirling combustor," 53rd AIAA Aerospace Science Meeting, No. AIAA 2015-0167, 2015.

${ }^{12}$ Koo, H., Raman, V., Mueller, M. E., and Geigle, K. P., "Effect of Pressure on Soot Formation in a Model Aircraft Combustor," Submitted to Proceedings of the Combustion Institute.

${ }^{13}$ Koo, H., Hassanaly, M., Raman, V., Mueller, M. E., and Geigle, K. P., "Large-eddy simulation of soot formation in a model gas turbine combustor," ASME Turbo Expo 2016, No. GT2016-57952, 2016.

${ }^{14}$ Raman, V. and Fox, R. O., "Modeling of fine-particle formation in turbulent flames," Annual Review of Fluid Mechanics, Vol. 48, 2016, pp. 159-190.

${ }^{15}$ Attili, A., Bisetti, F., Mueller, M. E., and Pitsch, H., "Formation, growth, and transport of soot in a three-dimensional turbulent non-premixed jet flame," Combustion and Flame, Vol. 171, No. 7, 2014, pp. 1849-1865.

${ }^{16}$ Pierce, C. D. and Moin, P., "Progress-variable Approach for Large-Eddy Simulation of Non-Premixed Turbulent Combustion," Journal of Fluid Mechanics, Vol. 504, 2004, pp. 73-97.

${ }^{17}$ Mueller, M. E. and Pitsch, H., "LES models for sooting turbulent nonpremixed flames," Combustion and flame, Vol. 159, 2012, pp. 2166-2180.

${ }^{18}$ Mueller, M. E., Large eddy simulation of soot evolution in turbulent reacting flows, Ph.D. thesis, Stanford University, 2012.

${ }^{19}$ Mueller, M. E., Blanquart, G., and Pitsch, H., "Hybrid Method of Moments for Modeling Soot Formation and Growth," Combustion and Flame, Vol. 156, 2009, pp. 1143-1155.

${ }^{20}$ Mueller, M. E. and Pitsch, H., "Large eddy simulation subfilter modeling of soot-turbulence interactions," Physics of fluids, Vol. 23, 2011, pp. 115104

${ }^{21}$ Blanquart, G. and Pitsch, H., Combustion Generated Fine Carbonaceous Particles, Karlsruhe University Press, 2009.

${ }^{22}$ Frenklach, M. and Wang, H., "Detailed modeling of soot particle nucleation and growth," Proceedings of the Combustion Institute, Vol. 23, 1991, pp. 1559-1566.

${ }^{23}$ Blanquart, G., Pepiot-Desjardins, P., and Pitsch, H., "Chemical mechanism for high temperature combustion of engine relevant fuels with emphasis on soot precursors," Combustion and Flame, Vol. 156, No. 3, 2009, pp. 588-607.

${ }^{24}$ Narayanaswamy, K., Blanquart, G., and Pitsch, H., "A Consistent Chemical Mechanism for Oxidation of Substituted Aromatic Species," Combustion and Flame, Vol. 157, 2010, pp. 1879-1898.

${ }^{25}$ Lietz, C., Heye, C., Raman, V., and Blunck, D., "Flame Stability Analysis in an Ultra Compact Combustor Using Large-Eddy Simulation," 52nd AIAA Aerospace Science Meeting, No. AIAA 2014-1022, 2014.

${ }^{26}$ Lietz, C., Donde, P., Raman, V., and Martin, S., "Large eddy simulation/Eulerian probability density function approach for simulating hydrogen-enriched gas turbine combustors," ASME Turbo Expo 2012, No. GT2012-68369, 2012.

${ }^{27}$ Lietz, C., Hassanaly, M., and Raman, V., "Large Eddy Simulation of Flame Flashback in Swirling Premixed CH4/H2-Air Flames," 53rd AIAA Aerospace Science Meeting, No. AIAA 2015-0844, 2015.

${ }^{28}$ Hassanaly, M., Large eddy simulations of boundary layer flashback in wall-bounded flows, Master's thesis, The University of Texas at Austin, 2015.

${ }^{29}$ Morinishi, Y., "Skew-symmetric form of convective terms and fully conservative finite difference schemes for variable density low-Mach number flows," Journal of Computational Physics, Vol. 229, 2010, pp. 276-300. 